ORIGINAL ARTICLE

\title{
Are ethnic differences in lung function explained by chest size?
}

\author{
A L Whittaker, A J Sutton, C S Beardsmore
}

Arch Dis Child Fetal Neonatal Ed 2005;90:F423-F428. doi: 10.1136/adc.2004.062497

See end of article for authors' affiliations .....................

Correspondence to: Dr C Beardsmore, Department of Child Health, Robert Kilpatrick Clinical Sciences Building, University of Leicester, Leicester Royal Infirmary, PO Box 65, Leicester LE2 7LX, UK; csb@le.ac.uk

Accepted 1 February 2005 Published Online First 4 May 2005 erences in lung function (LF) are recognised in adults and children. Most prediction Background: Ethnic differences in lung function (LF) are recognised in adults and children. Most prediction
equations for LF are derived from whites, so non-whites are at risk of erroneous assessment. It was hypothesised that differences in chest dimensions would explain differences in LF between Asian (Indian) and white schoolchildren.

Aims: To quantify the impact of chest dimensions on LF, which would inform our understanding of ethnic differences that have implications for health care.

Methods: Children aged 6-11 were studied in school. A questionnaire provided information on ethnicity and respiratory health. Spirometry was used to record FVC, FEV, $\mathrm{FEF}_{25-75}$, and PEF. Weight, height, sitting height, and chest dimensions (chest height, circumference, antero-posterior and transverse diameters) were measured.

Results: Data were obtained from 294 healthy children. Standing height was the most important predictor of LF. Ethnicity was an independent predictor for all LF measures except PEF, where the effect was marginal. FVC in whites was $13.4 \%$ bigger than in Asians of the same height, and the $\mathrm{FEV}_{1}$ was $10.6 \%$ greater in whites. The influence of chest dimensions on lung function was trivial. Body mass index was smaller in Asians but did not explain differences in LF.

Conclusions: Differences in chest dimensions did not explain the substantial effect of ethnicity on LF. Mechanisms whereby ethnicity exerts its influence may include differences in inspiratory muscle strength or lung compliance but remain speculative. Nevertheless it remains imperative that ethnic differences are recognised when interpreting LF tests.
$\mathrm{E}$ thnic differences in lung function have been recognised in adults,,$^{1-4}$ infants, ${ }^{5}$ and children..$^{6-14}$ Despite this, many lung function laboratories fail to employ race specific reference values, ${ }^{15}$ although this may reflect a lack of available equations. Use of inappropriate prediction equations can lead to inaccurate interpretation of lung function, which may have consequences for an individual (albeit rarely) and is certainly important for research studies. ${ }^{10}{ }^{16}{ }^{17} \mathrm{It}$ is therefore imperative that ethnic differences in lung function are acknowledged by development and use of appropriate reference values.

The reasons for ethnic differences in lung function are not completely understood. In some ethnic groups the proportions of leg length to body height are different, and here the use of sitting height as the primary predictor diminishes the differences. ${ }^{13}$ Socioeconomic status can be a confounding variable $^{18}$ but ethnic differences remain significant when adjustments have been made for this. ${ }^{19}$ There is some evidence that differences in chest dimensions in adults may contribute to ethnic differences in lung function. ${ }^{20}$ A direct comparison of white, Asian (Indian) and black children from the UK has shown ethnic differences in lung function, ${ }^{7}$ and we wanted to test the hypothesis that reduced lung function in Asian children would be explained by differences in chest size. The study was designed to characterise differences in spirometry and chest dimensions in Asian and white children. We aimed to go beyond simple reporting of ethnic differences and quantify the impact of chest dimensions on lung function, which would inform our understanding of ethnic differences that have important implications for health care.

\section{METHODS}

\section{Recruitment}

This study took place in Leicester, where $28 \%$ of the people have ethnic origins in the Indian subcontinent (Asian). It had the approval of Leicestershire Research Ethics Committee. Power calculations prepared in advance indicated that a study of 200 children ( 50 for both genders in each ethnic group) would have a power of $80 \%$ to detect a difference of $7 \%$ in forced vital capacity, if such a difference existed.

Children aged 6-11 were recruited from nine city primary schools. They took home an information pack containing a consent form and a questionnaire to establish ethnicity and eligibility and provide information on respiratory symptoms and smoke exposure. These were returned prior to measurements taking place in schools. In order not to discriminate against children of other ethnic origins or of mixed race we allowed all those with parental consent to participate, although we report only the comparison of whites and Asians.

Children were excluded if they had a history of cardiopulmonary disease, chest wall deformity, or preterm delivery. Asthma was not an exclusion criterion unless the child required daily medication. Children with a body mass index (BMI) above $30 \mathrm{~kg} / \mathrm{m}^{2}$ were excluded from analysis.

Abbreviations: $\mathrm{BMI}$, body mass index; $\mathrm{FEV}_{1}$, forced expiratory volume in 1 second; FVC, forced vital capacity; LF, lung function; PEF, peak expiratory flow 

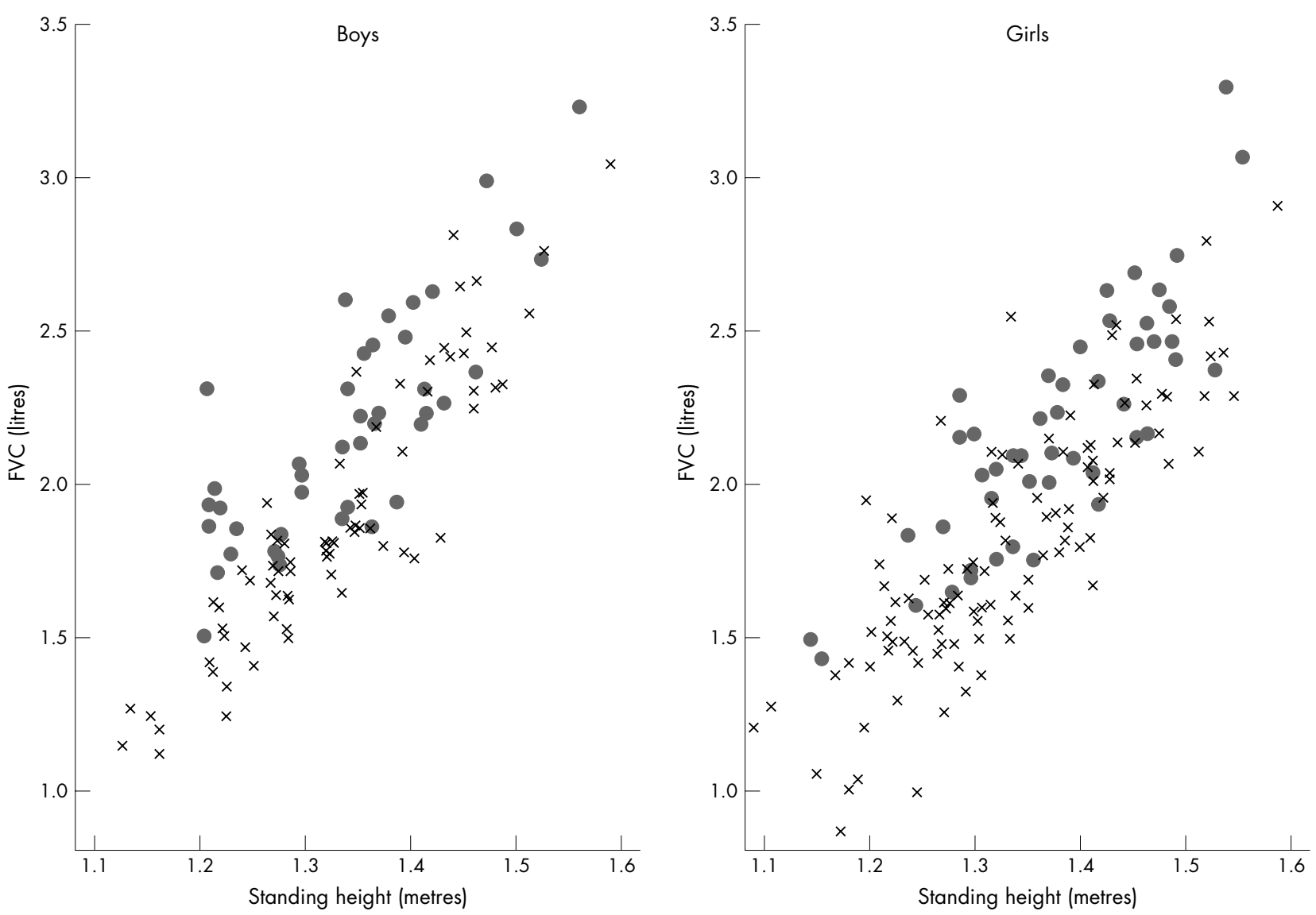

Figure 1 Scatter plots of FVC versus standing height for boys and girls. Circles, white; crosses, Asian.

\section{Equipment and methods}

Anthropometry

Standing height was measured at full inspiration with a portable height measure. Measurements were made in duplicate, to the nearest millimetre, and the mean value reported. Sitting height was measured with the child seated on a flat stool. Weight was measured on electronic scales to the nearest $0.1 \mathrm{~kg}$ wearing light clothing only. Body mass index (BMI) and z scores for height, weight, and BMI were calculated. ${ }^{21} 22$

Children were asked to remove all clothing from above the waist. Anatomical landmarks were palpated and marked. Chest circumference, transverse diameter, and anteriorposterior $(\mathrm{A}-\mathrm{P})$ diameter were measured at the level of the mesosternale (4th costosternal articulation). Chest height was measured from the mid-clavicular point to the lower rib border. Measurements were made at end tidal expiration. An anthropometric tape measure was used for chest circumference and height and a Harpenden anthropometer for transverse and A-P diameters. Two estimations of chest volume were made: (1) the chest was treated as a box (volume $=$ chest height $\times$ transverse diameter $\times \mathrm{A}-\mathrm{P}$ diameter); and (2) as a cylinder (volume $=$ chest height $\times$ $\pi r^{2}$, where radius was derived from the chest circumference ( circumference $=2 \pi \mathrm{r})$ ).

If a child did not want to undress, measurements were made over the clothing so that he/she did not feel rejected. Such measurements were subsequently discarded. Where a child retained only a light undergarment so that anatomical landmarks could be palpated and marked by pulling the garment down at the neck or armholes, measurements were made as usual and the subsequent statistical analysis adjusted for any systematic difference.
Spirometry

Spirometry was performed using a Jaeger Masterscope (a portable laptop spirometer equipped with pneumotachograph) and software (Labmanager version 5.42). Equipment was calibrated before each recording session using a 1 litre syringe. The child was seated and wore a nose clip. Instructions and a demonstration were given and the child was allowed to practise without the equipment. A minimum of 3 and a maximum of 8 manoeuvres were performed. ${ }^{23}$

The following measurements were made: forced vital capacity $(\mathrm{FVC})$, forced expired volume in 1 second $\left(\mathrm{FEV}_{1}\right)$, peak expiratory flow (PEF), and forced expiratory flow between $75 \%$ and $25 \%$ FVC $\left(\mathrm{FEF}_{75-25}\right)$. The operator rejected technically unsatisfactory recordings and examined data for reproducibility. The highest two values of FVC and $\mathrm{FEV}_{1}$ were required to be within $5 \%$ of each other. We report the largest values of PEF, FVC, and $\mathrm{FEV}_{1}$, even if they come from different curves. $\mathrm{FEF}_{75-25}$ came from the curve that gave the greatest sum of FVC plus $\mathrm{FEV}_{1} \cdot{ }^{23}$

\section{Statistical methods}

Following preliminary graphical and tabular examination of the data, multiple linear regression analyses examining the simultaneous and independent effect of the demographic and clinical characteristics (ethnicity, gender, age, weight, standing height, BMI, chest circumference, chest height, transverse diameter, $\mathrm{A}-\mathrm{P}$ diameter, chest volume) and each measure of lung function (FVC, $\mathrm{FEV}_{1}, \mathrm{PEF}$, and $\mathrm{FEF}_{75-25}$ ) were carried out. A binary indicator variable recording whether a light undergarment was worn was included in the modelling to account for any impact on chest measurements. 
Table 1 Descriptive statistics for children split by gender and ethnic origin

\begin{tabular}{|c|c|c|c|c|c|}
\hline & \multicolumn{2}{|l|}{ Girls } & \multicolumn{2}{|l|}{ Boys } & \multirow[b]{2}{*}{ p value } \\
\hline & White & Asian & White & Asian & \\
\hline Sample size (range) & $42-49$ & $103-116$ & $42-44$ & $69-85$ & \\
\hline Age (years) & $9.60(1.34)$ & $8.99(1.50)$ & $9.04(1.33)$ & $8.83(1.47)$ & \\
\hline Standing height $(\mathrm{m})$ & $1.37(0.10)$ & $1.33(0.11)$ & $1.34(0.09)$ & $1.33(0.10)$ & 0.050 \\
\hline Standing height $\mathrm{z}$ score* & $0.20(0.89)$ & 0.07 (1.09) & $0.16(0.94)$ & $0.10(1.21)$ & 0.89 \\
\hline Weight $(\mathrm{kg})$ & $35.2(8.2)$ & $30.6(8.6)$ & $33.3(8.7)$ & $31.1(9.7)$ & 0.012 \\
\hline Weight z score* & $0.49(0.98)$ & $0.04(1.12)$ & $0.65(1.04)$ & $0.24(1.47)$ & 0.021 \\
\hline BMI $\left(\mathrm{kg} / \mathrm{m}^{2}\right)$ & $18.4(3.1)$ & $17.0(2.9)$ & $18.3(3.3)$ & $17.3(3.2)$ & 0.011 \\
\hline BMI z score* & $0.51(1.16)$ & $0.006(1.2)$ & $0.79(1.17)$ & $0.30(1.44)$ & 0.0032 \\
\hline Chest circumference $(\mathrm{cm})$ & $66.8(6.2)$ & $64.2(7.7)$ & $67.6(6.6)$ & $65.3(7.9)$ & \\
\hline Chest height $(\mathrm{cm})$ & $23.9(2.6)$ & $23.0(2.5)$ & $23.9(2.1)$ & $23.6(2.3)$ & \\
\hline Transverse diameter $(\mathrm{cm})$ & $19.6(1.5)$ & $18.8(1.9)$ & $20.3(1.6)$ & $19.5(2.0)$ & \\
\hline A-P diameter $(\mathrm{cm})$ & $13.8(1.25)$ & $13.1(1.5)$ & $14.2(1.4)$ & $13.6(1.6)$ & \\
\hline Chest size as a box (I) & $6.58(1.51)$ & $5.76(1.71)$ & $7.00(1.66)$ & $6.39(1.95)$ & \\
\hline Chest size as cylinder (I) & $8.65(2.32)$ & $7.79(2.64)$ & $8.88(2.40)$ & $8.27(2.88)$ & \\
\hline FVC (I) & $2.19(0.39)$ & $1.80(0.41)$ & $2.19(0.38)$ & $1.89(0.43)$ & \\
\hline $\mathrm{FEV}_{1}$ (I) & $1.96(0.35)$ & $1.68(0.36)$ & $1.93(0.32)$ & $1.69(0.36)$ & \\
\hline PEF (I/s) & $4.22(0.87)$ & $3.83(0.88)$ & $4.12(0.90)$ & $3.87(0.93)$ & \\
\hline $\mathrm{FEF}_{75-25}(\mathrm{l} / \mathrm{s})$ & $2.23(0.57)$ & $2.09(0.59)$ & $2.10(0.62)$ & $1.91(0.57)$ & \\
\hline
\end{tabular}

In all regression modelling, non-linear trends in the continuous variables such as standing height were considered by including polynomial terms. Similarly, interactions between variables were also considered. These potentially allow non-additive effects of variables to be modelled. A manual stepwise (forwards-backwards) variable selection procedure was adopted, retaining terms if they were significant at the 5\% level (except for smoking which had to be significant at the $10 \%$ level and ethnicity which was retained regardless of statistical significance). Inspection of the standardised residuals checked that modelling assumptions were met. The statistical package SPSS version 9 was used for all statistical analysis.

This study was approved by the Leicestershire Research Ethics Committee Ref. No. 6341 (project no. 7173).

\section{RESULTS}

Three hundred and seven children were tested and 294 included in the analysis. Those excluded were not of Asian or white ethnicity (12 children) or had a BMI greater than $30 \mathrm{~kg} / \mathrm{m}^{2}$ (one child).

Summary demographics and chest dimension statistics are shown (table 1) and data on doctor diagnosed asthma and maternal smoking are provided (table 2). The modelling of chest dimensions is available from the authors on request. The white girls were fractionally older and taller than the other groups but there was extensive overlap between all groups (fig 1). The analysis technique (multiple linear regression) does not require that the groups be perfectly matched for age, height, and weight. We could not obtain complete data on chest measurements as some children were unwilling to undress ( 19 girls and 3 boys). Spirometry data from 29 children were missing or incomplete, usually attributable to poor technique.

Doctor diagnosed asthma was more prevalent among white than Asian children and among boys than girls (irrespective of ethnicity). All three smoking variables had higher rates in whites than Asians. The incidence of hay fever and allergies did not differ between ethnic groupings, but a history of eczema was marginally commoner in white children.

\section{Respiratory function}

Height was the most important predictor of lung function. Preliminary cross-correlation analysis showed that substituting sitting height for standing height did not explain any more of the variability than standing height alone (data not shown).

Figure 1 presents a scatter plot of FVC against height for boys and girls separately, distinguishing ethnic origin. This is representative of plots for other indices of lung function. Multiple linear regression analysis (table 3) showed that height ${ }^{2}$ significantly improved the fit of the models for FVC and $\mathrm{FEV}_{1}$. Chest size calculated as a box (included in preference to chest size calculated as a cylinder, although the improvement was marginal) was also a predictor for FVC and $\mathrm{FEV}_{1}$. Chest height was the best chest dimension

Table 2 Descriptive data on doctor diagnosed asthma and exposure to environmental tobacco smoke for children split by gender and ethnic origin

\begin{tabular}{|c|c|c|c|c|c|c|c|c|c|c|}
\hline & \multicolumn{2}{|c|}{ Doctor diagnosed asthma } & \multicolumn{3}{|c|}{$\begin{array}{l}\text { Number of cigarettes smoked by } \\
\text { mother per day }\end{array}$} & \multicolumn{2}{|c|}{$\begin{array}{l}\text { Mother smoked during } \\
\text { pregnancy }\end{array}$} & \multicolumn{3}{|c|}{$\begin{array}{l}\text { Number of cigarettes smoked by other } \\
\text { household members per day }\end{array}$} \\
\hline & No & Yes & 0 & $1-10$ & $11+$ & No & Yes & 0 & $1-10$ & $11+$ \\
\hline \multicolumn{11}{|l|}{ Girls } \\
\hline White & $39(79.6 \%)$ & $10(20.4 \%)$ & $33(67.3 \%)$ & $7(14.3 \%)$ & $9(18.3 \%)$ & $35(72.9 \%)$ & $13(27.1 \%)$ & $36(73.5 \%)$ & $3(6.1 \%)$ & $10(20.4 \%)$ \\
\hline Asian & $112(96.6 \%)$ & $4(3.4 \%)$ & $113(98.3 \%)$ & $2(1.7 \%)$ & $0(0 \%)$ & $114(99.1 \%)$ & $1(0.9 \%)$ & $92(79.3 \%)$ & $17(17.4 \%)$ & $7(6.0 \%)$ \\
\hline \multicolumn{11}{|l|}{ Boys } \\
\hline White & $28(66.7 \%)$ & $14(33.3 \%)$ & 27 (64.3\%) & $2(4.8 \%)$ & $13(30.9 \%)$ & $30(71.4 \%)$ & $12(28.6 \%)$ & $28(66.7 \%)$ & $5(11.9 \%)$ & $9(21.4 \%)$ \\
\hline Asian & $74(87.1 \%)$ & $11(12.9 \%)$ & $84(98.8 \%)$ & $1(1.2 \%)$ & $0(0 \%)$ & $83(97.6 \%)$ & $2(2.4 \%)$ & $62(72.9 \%)$ & $19(22.4 \%)$ & $4(4.7 \%)$ \\
\hline
\end{tabular}


Table 3 Multiple linear regression predictive equations for lung function outcomes FVC, $\mathrm{FEV}_{1}, \mathrm{PEF}$, and $\mathrm{FEF}_{75-25}{ }^{*}$

\begin{tabular}{lccc}
\hline Variable & $\boldsymbol{\beta}$ & $\mathbf{9 5 \%} \mathrm{Cl}$ for $\boldsymbol{\beta}$ & p value \\
\hline $\begin{array}{l}\text { Predictive equation for outcome FVC (I) } \\
\text { Constant }\end{array}$ & 2.218 & $(-1.487$ to 5.924$)$ & 0.24 \\
$\begin{array}{l}\text { Gender (additive effect of being female } \\
\text { compared to male) }\end{array}$ & -0.075 & $(-0.127$ to -0.024$)$ & 0.004 \\
Ethnic origin (additive effect of being Asian & -0.226 & $(-0.280$ to -0.172$)$ & $<0.001$ \\
compared to white) & -3.337 & $(-8.872$ to 2.198$)$ & 0.24 \\
Standing height $(\mathrm{m})$ & 2.250 & $(0.182$ to 4.318$)$ & 0.033 \\
Standing height ${ }^{2}\left(\mathrm{~m}^{2}\right)$ & 0.053 & $(0.032$ to 0.074$)$ & $<0.001$
\end{tabular}

Predictive equation for outcome $\mathrm{FEV}_{1}$ (I) Constant

$3.346 \quad(-0.208$ to 6.899$) \quad 0.065$

Ethnic origin (additive effect of being Asian

compared to white)

Standing height $(\mathrm{m})$

Standing height ${ }^{2}\left(\mathrm{~m}^{2}\right)$

Chest volume calculated as a box (I)

$(-0.231$ to -0.128

$<0.001$

$-4.966$

$(-10.274$ to 0.343$) \quad 0.067$

$(0.785$ to 4.753$) \quad 0.006$

$\mathrm{n}=247$; adjusted $\mathrm{R}^{2}=0.72$

Predictive equation for outcome PEF (I/s)

Constant

Ethnic origin (additive effect of being Asian

compared to white)

Standing height $(\mathrm{m})$

Chest height $(\mathrm{cm})$

$\begin{array}{ccr}-3.746 & (-4.879 \text { to }-2.613) & <0.001 \\ -0.170 & (-0.344 \text { to } 0.003) & 0.055 \\ & & \\ 4.835 & (3.602 \text { to } 6.068) & <0.001 \\ 0.0565 & (0.006 \text { to } 0.107) & 0.028 \\ n=251 ; \text { adjusted } R^{2}=0.45 & \end{array}$

Predictive equation for outcome $\mathrm{FEF}_{75-25}(\mathrm{l} / \mathrm{s})$

Constant
Ethnic origin (additive effect of being Asian

compared to white)

Standing height $(\mathrm{m})$

Asthma

$-1.797$

$-0.195$

$(-2.641$ to -0.952$)$

$(-0.344$ to -0.046$)$

$<0.001$

3.026

(2.414 to 3.637$)$

$(-0.415$ to -0.041$)$

$(-0.405$ to 0.195$)$

Mother smokes 1-10 cigarettes per day

$-0.228$

$-0.105$

$-0.315$

$(-0.562$ to -0.068$)$

0.002

Mother smokes $11+$ cigarettes per day

$\mathrm{n}=263$; adjusted $\mathrm{R}^{2}=0.30$

*Ethnic origin automatically included in the model. Other terms retained if $p<0.05$ (smoking $p<0.10$ ) or higher order term in covariate included.

predictor for PEF, while no chest dimension variables significantly improved the fit of the model for $\mathrm{FEF}_{75-25}$.

Gender was an important predictor only for FVC. Asthma and maternal smoking were included only for the $\mathrm{FEF}_{75-25}$ outcome. Smoking by other household members did not affect respiratory function. Eczema had no effect on any lung function variable.

Ethnic origin was retained in all models and remained a highly significant predictor for $\mathrm{FVC}, \mathrm{FEV}_{1}$, and $\mathrm{FEF}_{75-25}$ outcomes ( $p<0.001, p=0.001$, and $p=0.01$ respectively), while its effect was marginal for PEF prediction $(p=0.055)$. All four models consistently estimated that Asians had lower spirometry readings having adjusted for demographic and chest dimension variables. No interaction terms significantly improved the fit of the model for any of the respiratory measurements. Hence, the models suggest that differences in spirometry between Asians and whites are constant across the height range of this study. The predictive ability of models for FVC and $\mathrm{FEV}_{1}$ are good with $78 \%$ and $72 \%$ of variation explained respectively, while the predictive ability of the PEF model is moderate (adjusted $\mathrm{R}^{2}=45 \%$ ) and the $\mathrm{FEF}_{75-25}$ model has relatively poor predictive ability (adjusted $\left.\mathrm{R}^{2}=30 \%\right)$.

\section{DISCUSSION}

We have characterised differences in lung function and chest dimensions in Asian and white children aged 6-11 years and generated predictive equations to describe the data. Ethnicity was an important independent predictor for $\mathrm{FVC}, \mathrm{FEV}_{1}$, and $\mathrm{FEF}_{25-75}$ and had a marginal effect on the prediction of PEF. On average, white children had an FVC $13.39 \%$ bigger and an $\mathrm{FEV}_{1} 10.63 \%$ bigger than their Asian counterparts. Variations in chest wall dimensions did not explain ethnic differences in lung function.

The modelling strategy we adopted in this study was based on the original measurements without transformations. An alternative approach would be to log transform the anthropometry and lung function measurements. If the differences in lung function between ethnic groups were proportional, then a logarithmic transformation would most readily facilitate such a comparison. The proportional differences can then readily be expressed as a percentage effect. ${ }^{24}$ We applied this modelling strategy as a secondary analysis to investigate whether it better fitted the data and found that: (1) the magnitude of the ethnicity effect was essentially unaltered; and (2) the amount of variability explained by the model was unchanged for FVC, $\mathrm{FEV}_{1}$, and PEF and marginally worse for $\mathrm{FEF}_{25-75}$ (results not shown). We have therefore retained the original analysis, but acknowledge that a log transformation approach may be superior for a data set obtained from children over a wider range of ages and heights.

\section{Differences in lung function}

Height was the single most important predictor of lung function. Ethnicity exerted significant effects that were not 
explained by differences in chest dimensions. We did not find evidence of interactive effects of height and ethnicity for any outcome.

Preliminary cross-correlation analysis showed that sitting height was no better predictor of lung function than standing height. This suggests that there are no major differences in the ratio of leg length to trunk length in our groups of children, in contrast to studies comparing blacks and whites. $^{3} 121920$ Sitting height, although potentially useful, cannot be measured as reproducibly as standing height ${ }^{1325}$ and was not therefore considered further.

The improvements seen in the amount of the variability explained by the equations when an additional term for a chest dimension was included were small and not sufficient to warrant routine inclusion. Although chest dimensions might theoretically be better at predicting lung volumes than height, the reproducibility of the measurements may be poorer. ${ }^{26}$

We observed an effect of maternal smoking on respiratory function. Smoking over 10 cigarettes per day was associated with a reduction in $\mathrm{FEF}_{25-75}$. Our study was not designed to investigate the influence of exposure to smoking on respiratory function, and the low rates of smoking among Asian mothers limits the power to examine any interactions between ethnicity and smoke exposure.

Our prediction equations for lung volumes generate comparable values to other studies in white and Asian subjects born in England. ${ }^{727}$ Comparing our results to studies conducted in India, white children had lung volumes approximately $17 \%$ larger than Indian children. ${ }^{28} 29$ The Asian children living in Leicester had lung volumes approximately $6 \%$ greater than those in India. The reasons for this probably relate to socioeconomic factors including nutrition and exposure to pollution, although genetic differences within subsets of the same ethnic or racial groups cannot be ruled out. Socioeconomic status influences pulmonary function in adults, ${ }^{30}$ but ethnic differences remain, even when the study groups are restricted to young adults of similar socioeconomic status, ${ }^{4}$ or when adjustments are made for socioeconomic status and level of education. ${ }^{19}$ We did not assess socioeconomic status in our study, but did not anticipate major differences between groups because most children live within walking distance of their primary school and so may live in similar housing and have similar exposure to outdoor pollutants. Similar socioeconomic status would not, however, imply similar nutritional status, and we have no information on diet in the children in this study.

FVC in boys was on average $6.2 \%$ greater than in girls, consistent with other studies that have reported gender differences between 5\% and 8.5\%. ${ }^{722731}$ We found that gender was not an independent predictor of $\mathrm{FEV}_{1}$ when other covariates were considered. It is not until after puberty that the major divergence between boys and girls occurs, with males ultimately having substantially greater lung volumes for height than females. ${ }^{32}$ If there was any difference in the timing of puberty in the two ethnic groups such that the white children went through puberty at an earlier age, this could enhance apparent ethnic differences in lung function. Although some of our oldest children would have been in the early stages of puberty, the effects of puberty on lung function are relatively late ${ }^{32}$ and we would not expect them to have had a major impact on the population we have studied. We have been unable to find evidence for a difference in age of puberty between Asian and white children.

\section{Lung function and chest dimensions}

In a study involving chest radiographs of 38 adults, Caucasians had larger chest cavities than their Chinese and Indian counterparts. ${ }^{20}$ Caucasians had wider chests than the

\section{What is already known on this topic}

Ethnic differences in lung function are recognised in children but the underlying basis for this is unknown

\section{What this study adds}

Differences in lung function between Asian and white children of primary school age have been confirmed. They were not explained by differences in chest wall dimensions, which were trivial

other races, in accordance with our findings. A review of data from Caucasian, Chinese, and Indian subjects concluded that there was relatively little difference in RV between these three groupings, implying that a larger total lung capacity (TLC) is responsible for the larger FVC and $\mathrm{FEV}_{1}{ }^{33}$ TLC reflects the size of the thoracic cage, the strength of the inspiratory muscles, and the compliance of the lungs and chest wall. Our findings suggest that the last two factors are more likely to explain ethnic differences and warrant further study.

In summary, we have characterised differences in lung function between Asian and white children within the same community. Differences in chest dimensions did not explain the substantial effect of ethnicity on lung volumes, which merits further study. In view of the potential for misclassification of clinical status if ethnicity is ignored, we emphasise the need for those who measure and interpret tests of respiratory function to make allowance for ethnicity.

\section{ACKNOWLEDGEMENTS}

We thank Mrs Jennifer Westaway for practical assistance, Emeritus Professor Peter Jones for advice, the Leicestershire Local Education Authority for permission to carry out the study, and the school staff, parents, and children for their help and participation.

\section{Authors' affiliations}

A L Whittaker, Department of Child Health, Leicester Warwick Medical School, UK

A J Sutton, Department of Epidemiology and Public Health, University of Leicester, UK

C S Beardsmore, Institute for Lung Health, Leicester, UK

ALW was in receipt of a grant from PPD Development Clinic

Competing interests: none

\section{REFERENCES}

1 Schoenberg JB, Beck GJ, Bouhuys A. Growth and decay of pulmonary function in healthy blacks and whites. Respir Physiol 1978;33:367-93.

2 Rossiter CE, Weill $\mathrm{H}$. Ethnic differences in lung function: evidence for proportional differences. Int J Epidemiol 1974;3:55-61.

3 Jacobs DR Jr, Nelson ET, Dontas AS, et al. Are race and sex differences in lung function explained by frame size? The CARDIA Study. Am Rev Respir Dis 1992;146:644-9.

4 Korotzer B, Ong S, Hansen JE. Ethnic differences in pulmonary function in healthy nonsmoking Asian-Americans and European-Americans. Am J Respir Crit Care Med 2000;161:1101-8.

5 Stocks J, Henschen M, Hoo A-F, et al. Influence of ethnicity and gender on airway function in preterm infants. Am J Respir Crit Care Med 1997; 156:1855-62

6 Binder RE, Mitchell CA, Schoenberg JB, et al. Lung function among black and white children. Am Rev Respir Dis 1976;1 14:955-9.

7 Patrick JM, Patel A. Ethnic differences in the growth of lung function in children: a cross-sectional study in inner-city Nottingham. Ann Hum Biol 1986;13:307-15.

8 Boggs PB, Stephens AL, Walker RF, et al. Racially specific reference standards for commonly performed spirometric measurements for black and white children, ages 9-18 years. Ann Allergy 1981;47:273-7.

9 Asher MI, Douglas C, Stewart AW, et al. Lung volumes in Polynesian children. Am Rev Respir Dis 1987;136:1360-5. 
10 Coultas DB, Howard CA, Skipper BJ, et al. Spirometric prediction equations for Hispanic children and adults in New Mexico. Am Rev Respir Dis 1988; 138:1386-92.

11 Strope GL, Helms RW. A longitudinal study of spirometry in young black and young white children. Am Rev Respir Dis 1984;130:1100-7.

12 Schwartz J, Katz SA, Fegley RW, et al. Sex and race differences in the development of lung function. Am Rev Respir Dis 1988;138:1415-21.

13 Hsi BP, Hsu KH, Jenkins DE. Ventilatory functions of normal children and young adults: Mexican-American, white, and black. III. Sitting height as a predictor. J Pediatr 1983;102:860-5.

14 Greenough A, Hird MF, Everett L, et al. Importance of using lung-function regression equations appropriate for ethnic origin. Pediatr Pulmonol $1991 ; 11: 207-11$.

15 Ghio AJ, Crapo RO, Elliott CG. Reference equations used to predict pulmonary function. Survey at institutions with respiratory disease training programs in the United States and Canada. Chest 1990;97:400-3.

16 Shaffer BA, Samet JM, Coultas DB, et al. Prediction of lung function in Hispanics using local ethnic-specific and external non-ethnic-specific prediction equations. Am Rev Respir Dis 1993;147:1349-53.

17 Quadrelli S, Roncoroni A, Montiel G. Assessment of respiratory function: influence of spirometry reference values and normality criteria selection. Respir Med 1999;93:523-35.

18 Myers JE. Differential ethnic standards for lung functions, or one standard for all? S Afr Med J 1984;65:768-72.

19 Harik-Khan RI, Fleg JL, Muller DC, et al. The effect of anthropometric and socioeconomic factors on the racial differences in lung function. Am J Respir Crit Care Med 2001:164:1647-54.

20 Donnelly PM, Yang TS, Peat JK, et al. What factors explain racial difference in lung volumes? Eur Respir J $1991 ; 4: 829-38$.

21 Cole TJ, Freeman JV, Preece MA. Body mass index reference curves for the UK, 1990. Arch Dis Child 1995;73:25-9.
22 Freeman JV, Cole TJ, Chinn S, et al. Cross sectional stature and weight reference curves for the UK, 1990. Arch Dis Child 1995;73:17-24.

23 ATS. ATS statement: Standardization of spirometry; 1994 update. Am J Respir Crit Care Med 1995; 152:1107-36.

24 Cole TJ. Sympercents: symmetric percentage differences on the $100 \log (\mathrm{e})$ scale simplify the presentation of log transformed data. Stat Med 2000;19:3109-25.

25 Ferris BG Jr, Stoudt HW. Correlation of anthropometry and simple tests of pulmonary function. Arch Environ Health 1971;22:672-6.

26 Schrader PC, Quanjer PH, Borsboom G, et al. Evaluating lung function and anthropometric growth data in a longitudinal study on adolescents. Hum Biol 1984;56:365-81.

27 Rosenthal M, Bain SH, Cramer D, et al. Lung function in white children aged 4 to 19 years. I: Spirometry. Thorax 1993;48:794-802.

28 Srivastava A, Kapoor RK, Misra PK, et al. Pulmonary function tests in normal Indian children and changes in respiratory disorders. Indian Pediatr 1995;32:629-34

29 Malik SK, Jindal SK. Pulmonary function tests in healthy children. Indian Pediatr 1985;22:677-81.

30 Jackson B, Kubzansky LD, Cohen S, et al. A matter of life and breath: childhood socioeconomic status is related to young adult pulmonary function in the CARDIA study. Int J Epidemiol 2004;33:271-8.

31 Johnston ID, Bland JM, Anderson HR. Ethnic variation in respiratory morbidity and lung function in childhood. Thorax 1987;42:542-8.

32 Rosenthal M, Bush A. Growing up with lung disease: the lung in transition to adult life. In: Bush A, Carlsen KH, Zach MS, eds. The European Respiratory Monograph 2002;19(7):1-24.

33 Yang TS, Peat J, Keena V, et al. A review of the racial differences in the lung function of normal Caucasian, Chinese and Indian subjects. Eur Respir $J$ $1991 ; 4: 872-80$. 